\title{
Transportasi Darat Bus Mega Mas, 1998-2017
}

\author{
Dyan Ayu Rasmi Pesona, Muh. Rasyid Ridha, La Malihu \\ Prodi Pendidikan Sejarah Fakultas Ilmu Sosial Universitas Negeri Makassar \\ ayusafiraputriaulia@gmail.com
}

\begin{abstract}
Abstrak
Tulisan ini bertujuan untuk mengetahui sejarah perusahaan PO. Mega Mas, pembahasan meliputi latar belakang sosial ekonomi para pendiri perusahaan angkutan jasa yang di beri nama PO Mega Mas dan untuk untuk mengetahui perkembangan pelayanan serta dampak keberadaan PO. Mega Mas. Hasil penelitian menunjukka bahwa PO Mega Mas adalah perusahaan otobus yang didirikan pada tahun 1998 atas ide dan gagasan dari alm. Bapak Mapong Cewang dan istrinya. Seperti diketahui bahwa di tahun 1998-an terjadi krisis moneter di Indonesia. Krisis melanda berbagai segi kehidupan yang menyebabkan lahirnya reformasi. Hal ini menimbulkan kesulitan sosial dan ekonomi, namun PO Mega Mas masih bisa bertahan sampai sekarang tidak lepas dari kerja keras untuk terus memperbaiki dan meningkatkan pelayanan yang baik kepada pelanggang sehingga banyak pelanggang yang betah dan menjadi pelanggang tetap PO Mega Mas. karena sangat menarik bahwa di tengah krisis seperti ini PO Mega Mas bias berdiri dan bertahan hingga sekarang. Peneltian ini bersifat deskriptif analisis dengan menggunakan metode historis, melalui tahapan kerja yang meliputi: (1)heuristik, dalam tahapan ini sumber diperoleh dari hasil wawancara kepada pihak terkait dalam hal ini yaitu istri dari pendiri PO Mega Mas yang bernama Kalli, kemudan diperkuat arsip dan juga buku-buku yang diperoleh dari perpustakaan wilayah provinsi Sulawesi Selatan, dan perpustakaan Jurusan Pendidikan Sejarah UNM. (2) kritik, (3)interpretasi dan (4) historiografi. Konsep ilmu sosial seperti Ekonomi, Sosiologi dan Antropologi juga digunakan untuk menganalisis masalah yang relevan
\end{abstract}

\section{Kata Kunci : Sejarah, Perusahaan dan Mega Mas}

\begin{abstract}
This study aims to determine the history of PO companies. Mega Mas, the discussion covers the socio-economic background of the founders of the transportation service company, which is named PO Mega Mas and to find out the development of services and the impact of the existence of PO. Mega Mas. The results showed that PO Mega Mas is an autobus company that was founded in 1998 on the ideas and ideas of the late. Mr. Mapong Cewang and his wife. As it is known that in the 1998s there was a monetary crisis in Indonesia. The crisis hit various aspects of life that led to the birth of reform. This has caused social and economic difficulties, but PO Mega Mas can still survive until now not out of hard work to continue to improve and improve good service to the grill so that many consumers who feel at home and become permanent consumers PO Mega Mas. because it is very interesting that in the midst of a crisis like this PO Mega Mas can stand and survive until now. This research is descriptive analysis using historical methods, through the stages of work which include: (1) heuristics, in this stage the source is obtained from interviews with related parties in this case the wife of the founder of PO Mega Mas named Kalli, then strengthened the archive and also books obtained from the regional library of South Sulawesi province, and the library of the Department of History UNM History. (2) criticism, (3) interpretation and (4) historiography. Social science concepts such as Economics, Sociology and Anthropology are also used to analyze relevant problems
\end{abstract}

Keywords: History, Company and Mega Mas

Vol. 6, No.3, Desember 2019, 50-57 |50 


\section{A. Pendahuluan}

Transportasi digunakan untuk memudahkan manusia dalam melakukan aktivitas sehari-hari. Dengan alat Transportasi, kita dapat menjangkau tempat yang ingin kita kunjungi dengan mudah dan dalam waktu yang relative singkat pula.

Sesuai dengan perkembangan zaman, kegiatan manusia dalam memenuhi tuntutan kebutuhan hidup akan mengalami perubahan seperti tuntutan pemenuhan kebutuhan barang-barang (pangan, sandang, papan) dan juga adanya kebutuhan manusia akan kegiatan sosial (hubungan berkeluarga dan bermasyarakat), serta kegiatan non fisik (menuntut ilmu, berekreasi, mengunjungi kerabat dll). Kegiatan kehidupan manusia seperti ini membutuhan keberadaan transpotasi untuk mendukung dan mempermudah manusia mendapatkan objek kebutuhannya itu. (Miro, 2012)

Pada mulanya, transportasi hanya menggunakan tenaga manusia dan selanjutnya dipermudah dengan memanfaatkan tenaga hewan. Pada tahap ini muncul penggunaan gerobak, pedati, dan cikar sebagai sarana pengangkut manusia atau barang dengan tenaga hewan sebagai pendereknya. Alat transportasi mengalami perkembangan setelah ditemukannya tenaga mesin sebagai alat transportasi yang lebih baik. Di Pulau Jawa perkembangan alat transportasi darat dengan menggunakan tenaga mekanik tidak lepas dari peran Pemerintah Hindia Belanda. Pemerintah pada waktu itu berupaya memajukan sarana transportasi yang lebih baik guna memudahkan pengangkutan hasil produksi perkebunan dari daerah-daerah di Jawa. Pemerintah Hindia Belanda menyediakan layanan transportasi bagi kelangsungan pengusahapengusaha swasta. (Salim, 2012)

Bus pertama muncul bersamaan dengan perkembangan mobil. Bus menjadi popular pada awal abad 21, karena perang dunia I. ketika itu kebanyakan sarana di alokasikan untuk kebutuhan perang dan banyaknya mobil pribadi, sehingga di perlukan alat transportasi lain yang dapat mengangkut banyak penumpang. Bus merupakan angkutan umum yang dapat memuat 27 penumpang. Tapi kini ada yang berukuran besar yang bisa memuat 35 penumpang bahkan ada yang bisa memuat sampai 45 penumpang. Hal inilah yang mendorong Bus diciptakan di Indonesia dan PO Mega Mas hadir sebagai salah perusahaan Bus. (Iskandar, 2017) Moda transportasi berkapasitas (berukuran) besar dalam daya angkut mempunyai berat lebih besar. Untuk melayani moda transportasi yang berkapasitas besar dan berat dibutuhkan tersedianya prasarana (jalan) yang mempunyai daya dukung (tekanan gandar jalan) yang lebih besar. Artinya kemajuan dalam sarana transportasi membutuhkan pula kemajuan dalam prasarana transportasi yang harus disediakan. (Adisasmita, 2011). PO Mega Mas dapat bertahan hingga sekarang ini tidak lepas dari usaha dan kerja keras dari para pengelola PO Mega Mas yang selalu meningkatkan pelayanan dengan cara memperbaiki layanan dan juga fasilitas dalam bus agar para penumpang bisa merasa nyaman dengan menggunakan jasa PO Mega Mas.

Kajian relevan dalam suatu karya ilmiah perlu untuk ditelusuri guna mencari tahu apakah ide pokok suatu kajian sudah diangkat oleh penulis lain atau belum. Penelitian ini berusaha untuk mengaji mengenai Transportasi Darat Bus Mega Mas.

Skripsi yang ditulis oleh Muliati tahun 2014 dengan Judul PO. Pipos Makassar 1957-1975. Dalam pembahasan skripsi ini, pembahasan difokuskan pada sejarah di dirikannya PO. PIPOS dan perkembangannya dalam hal pelayanan dan juga peranannya dalam pergerakan masyarakat. sumber ini di jadikan sebagai bahan referensi. (Muliati, 2014)

Skripsi yang ditulis oleh Hardiansyah Jabir MC pada tahun 2016 dengan judul Analisis Pendanaan Modal Kerja pada PO. Mega Mas. Skripsi ini berfokus pada Sejarah Sosial Ekonomi yang membahas 
tentang kebijakan pendanaan modal kerja yang di butuhkan perusahaan sedangkan penulis mengkaji tentang awal mula berdirinya perusahaan, perkembangan perusahaan dan juga dampak adanya perusahaan bagi masyarakat. sumber ini di jadikan sebagai sumber data tentang PO Mega Mas yang banyak terdapat di dalam skripsi ini. (Hardiansyah, 2016)

Kajian relevan penelitian ini tidak hanya skripsi tetapi juga terdapat pada jurnal yang berjudul "Strategi Pengembangan Usaha Transportasi Bus (Studi Kasus pada Perusahaan Otobus di Lombok)" milik Vivi Ria Putri dan Ritzky Karina M.R. Brahmana di tulis pada tahun 2015 yang membahas tentang gambaran kondisi PO NN dalam industry transportasi bus trayek Mataram-Taliwang dan mengenai perancangan strategi yang tepat untuk PO NN agar dapat memanfaatkan peluang dan kekuatan dalam melakukan persaingan di industri transportasi bus. (Brahmana, 2015) Sementara penulis lebih terfokuskan mengkaji tentang perkembangan PO Mega Mas dengan trayek Makassar-Sorowako.

\section{B. Metode Penelitian}

Metode berasal dari bahasa yunani mahedus yang artinya cara atau jalan. Metode dapat diartikan sebagai cara mendeati, mengamati, dan menjelaskan satu gejala dengan menggunakan landasan teori. (Silalahi, 2012) Metode sejarah dapat diartikan sebagai cara atau prosedur yang sistematis dalam merekonstruksi masa lampau. Metode sejarah bertujuan memastikan fakta masa lampau. Gejalagejala sosial dan kebudayaan merupakan lapangan kerja dari metode.

Penelitian ini adalah kajian sejarah dan tentunya dalam proses penulisannya menggunakan metode yang sesuai dengan kaidah keilmuan sejarah. Adapun tehaptahap penelitian sejarah dapat diuraikan sebagai berikut:

\section{Heuristik}

Heuristik merupakan langkah awal dari metode penelitian sejarah, dimana pada tahap ini seorang peneliti mencari dan mengupayakan penemuan atas sumber sejarah yang memiliki keterkaitan dengan objek penelitian.Sumber sejarah tersebut dapat berupa catatan, tradisi lisan, dan setiap titik atau secercah apapun yang memberikan penerangan bagi cerita

\section{Kritik}

Tahap kedua dalam penelitian sejarah adalah kritik sumber.Hasil yang ingin dicapai pada tahap ini adalah didapatnya sumber sejarah yang benar-benar memvberikan fakta guna merekonstruksi masa lalu, terdapat dua aspek yang harus diverifikasi yaitu Otentisitas atau keaslian sumber, dan kredibilitas atau tingkat kebenaran informasi dari sumber sejarah.

Jika tahap pertama suatu sumber sejarah tidak memenuhi syarat sebuah sumber sejarah (dari segi otentisitasnya), tidak perlu dilanjutkan verifikasi berikutnya. (Madjd, 2004)

\section{Interpretasi.}

Tahapan ini merupakan setelah kritik sumber. Sumber-sumber yang telah didapatkan perlu ditafsirkan oleh peneliti. Dalam tahap interpretasi, imajinasi seorang peneliti dibutuhkan untuk menafsirkan seluruh kejadian berdasarkan data-data yang terkumpul. Pada hakikatnya, interpretasi sejarah seringkali disebut dengan analisis data sejarah.

\section{Historiografi}

Tahap ini merupakan tahap terakhir dalam penelitian sejarah. Pada tahap ini peneliti akan menuliskan peristiwa sejarah tersebut dalam sebuah tulisan yang dalam penulisan, pemaparan dan pelaporan menggunakan tata cara tertentu. Dimana dalam hal ini, penelitian yang peneliti lakukan adalah penelitian dengan kajian keperpustakaan dan lapangan. Penulisan sejarah merupakan proses penjelasan dari semua kegiatan dalam proses penelitian sejarah. Pada tahap ini penulis mencoba untuk menggambarkan hasil penelitiannya. Dalam hal ini pada penelitian tentang Transportasi Darat Bus Mega Mas (19982017) 
C. Pembahasan

1. Perkembangan awal (1998 - 2003): Menghadapi Tantangan

PO Mega mas merupakan salah satu angkutan bus milik mandiri yang berdiri di tahun 1998 dimana modal yang digunakan pada awal membeli Bus sebanyak 3 unit bukanlah merupakan utang yang dipinjam di Bank tetapi modal yang telah ditabung selama beberapa tahun yang dikumpulkan dari usaha toko yang dimilik. PO yang berdiri saat terjadi krisis ekonomi ini merupakan PO yang berani bersaing terhadap PO bus yang ada saat itu seperti LIMAN, LITHA dan Damri. Beberapa bus yang ada pada saat itu merupakan bus yang sudah lama beroperasi untuk trayek Makassar - Sorowako. Hal ini merupakan salah satu tantangan tersendiri bagi PO Mega Mas untuk mampu mempertahankan armada busnya agar tetap berjalan dan dapat bersaing dengan PO yang sudah ada sebelumnya.

Pada awal beroperasi Kantor PO Mega Mas yang ada di Makassar dulunya berada di Terminal Daya. Untuk para penumpang yang ingin berangkat ke daerah tujuan masing-masing langsung menuju ke terminal untuk menunggu keberangkatan bus. Keadaan kantor PO Mega Mas yang ada di terminal Daya pada waktu itu tidak begitu luas dan bisa dikatakan tidak mencukupi namun hal itu dapat diatasi dengan cara bus yang datang dan berangkat pada waktu itu tidak bersamaan biasanya paling banyak berjumlah 2 unit saja. Selain menjadi tempat untuk menunggu kedatangan bus, kantor PO Mega Mas ini juga dijadikan tempat parkir untuk bus-bus yang datang tetapi dengan jumlah yang terbatas dikarenakan tempatnya tidak begitu luas

Pada awal beroperasi ditahun 1999 PO Mega Mas menggunakan bus yang bermerek Marcedesbenz. Pada waktu itu, bus yang digunakan berukuran $3 / 4$ yang dengan jumlah 3 unit bus. Bus yang memiliki AC berjumlah 1 unit bus sedangkan dua lainnya merupakan bus non AC. Bus dengan tipe Mercedesbenz pada umumnya mampu menampung penumpang sebanyak 40 sampai 43 orang. Tetapi bapak Mapong Cewang membuka beberapa kursi karena di anggap sangat padat, karena beliau ingin memberikan pelayanan terbaik untuk para penumpang jadi beliau merinisiatif untuk membuka beberapa kursi sehingga hanya tersisa 32 kursi, tujuannya menurut beliau adalah agar penumpang bisa merasa nyaman untuk beristirahat di atas bus selama perjalanan karena tidak sempit lagi. Pada saat itu bus yang biasa diberangkatkan ke daerah tujuan tidak selalu penuh kadang terdapat kursi yang kosong. Adapun penumpang yang biasanya menjadi langganan PO Mega Mas adalah karyawan dari PT. Inco ( pada saat ini di disebut dengan nama PT. Vale) dan pedagang yang ingin menjual dagangannya di kota. Karyawan ini juga langganan bapak Mapong Cewang di tokonya yang ada di Sorowako dan bapak Mapong Cewang memang memiliki kerja sama dengan PT. Inco.

Pada awal beroperasi PO Mega Mas banyak mendapatkan bantuan dari Direktur PT. Inco yang merupakan rekan kerja sama dengan bapak Mapong Cewang. pada awalnya, PO Mega Mas mendapatkan kesulitan masalah perisinan tempat untuk di jadikan kantor di Sorowako. Hal itu disebab kan karena bapak Mapong Cewang ini hanyalah seorang pendatang di Sorowako. Tetapi karena bapak Mapong Cewang sudah lama mendidirkan usaha yaitu toko yang menjual berbagai kebutuhan pokok dan sudah banyak membantu perusahaan PT. Inco jadi dengan bantuan Direktur PT. Inco pada saat itu, PO Mega Mas diberikan tempat yang mana sekarang menjadi kantor atau perwakilan PO Mega Mas di Sorowako yaitu di Transpot PT. Inco (kalli, 2019) Pada awal beroperasi PO Mega Mas memulai trayeknya dari Makassar Sorowako dengan jarak tempuh $604,6 \mathrm{~km}$ yang berangkat mulai pukul 07.00 malam sampai di tujuan sekitar pukul 09.00 pagi Wita dengan waktu perjalanan kurang lebih 15 jam lamanya dengan kondisi jalan pada 
saat itu masih banyak yang berlubang serta banyak jalan-jalan yang belum beraspal dan juga jalan yang sempit merupakan salah satu kendala selama diperjalanan sehingga membutuhkan waktu yang cukup lama untuk sampai ke tempat tujuan. Alasan pemilik memilih trayek Makassar Sorowako dikarenakan pemilik perusahaan otobis ini mempunyai usaha dan sudah lama menetap di Sorowako. Untuk keberangkatan bus dari Sorowako ke Makassar, bus berangkat pada pukul 07.00 dan tiba di Makassar sekitar pukul 08.00.

Pada tahun 2000, yang awalnya kantor PO Mega Mas di Makassar hanya berada di Terminal Daya akhirnya bapak H. Jabir sebagai pengelola PO Mega Mas membeli ruko untuk di jadikan kantor (Perwakilan) karena di terminal Daya tak lagi mau menerima bus yang tidak memiliki kantor di luar terminal. Ruko tersebut berada di Ruko Puri Kencana Sari Blok AC no. 1, Jl. Perintis Kemerdekaan KM. 8 yang sampai sekarang menjadi kantor PO Mega Mas. Luas kantor yang baru dibeli jauh lebih luas dari kantor yang ada di terminal jadi lebih mudah memberikan pelayanan yang baik untuk para penumpang karena di kantor baru ini disediakan ruang tunggu untuk penumpang, berbeda dengan kantor yang ada di terminal yang tidak memiliki ruang tunggu. Seteolah memiliki kantor atau perwakilan baru, penjualan tiket dialihkan ke Perwakilan baru yang berada di Jalan Perintis Kemerdekaan. Dan bongkar muatan penumpang dan barang-barang kiriman yang berasal dari Sorowako dialihkan juga ke perwakilan yang baru.

Penumpang yang ingin berangkat ke daerah tujuan yang memiliki rumah yang jaraknya jauh dari tempat perwakilan biasanya datang lebih awal ke perwakilan dengan membawa barang-barang yang akan mereka bawa nantinya. Sambil menunggu kedatangan bus para penumpang juga bisa beristarahat di tempat yang sudah disediakan. Ada tempat duduk-duduk di ruang tunggu juga perwakilan menyediakan Mushollah untuk para penumpang yang ingin menunaikan sholat. Pada saat itu, bus yang akan berangkat menjemput penumpang di Perwakilan dan juga penumpang yang menunggu di terminal.

Ditahun awal 2001, juga merupakan awal berdirinya perwakilan yang bertempat di Pangkajene Kabupaten Sidrap tepatnya di Jalan Sultan Hasanuddin. Alasan didirikannya perwakilan Mega Mas di Sidrap ini disebabkan karena Sidrap merupakan tempat asal bapak Mappong Cewang. Perwakilan ini didirikan di rumah bapak Mappong Cewang yang ada di Pankajene Sidrap. Perwakilan yang berada di Sidrap ini sangat berkembang pesat dan sangat ramai penumpang dengan tujuan ke Sorowako dan tujuan ke Manado. Selain itu, pengiriman barang juga ramai sehingga perwakilan ini setiap malamnya di padati oleh berbagai penumpang yang ingin membeli tiket. Berdasarkan pendapatan yang di raih perusahaan pada tahun 2001 adalah sebesar Rp. 2.564.671.183. dimana biaya operasionalnya sebesar Rp. 739.166.667 serta terdapat biaya variabel sebesar Rp. 1.722.301.078. maka melihat data tersebut PO Mega Mas memperoleh keuntungan operasional sebesar Rp. 65.203.439. biaya keuntungan yang diperoleh ini sangat kecil. Hal ini di sebabkan adanya penambahan armada Mega Mas rute Manado (Wellang, 2004)

Juni 2001 bapak Mapong Cewang yang merupakan pendiri dari PO Mega Mas pindah ke Manado. Usaha Mega Mas jalur Makassar - Sorowako diserahkan kepada sang anak yang bernama H. Jabir yang sekaligus merupakan pemegang perusahaan ke 2 PO Mega Mas. Saat berada di Manado lah bapak Mappong Cewang kemudian membuka rute perjalanan ManadoMakassar. Mobil dengan rute Makassar ke Manado merupakan mobil bus kecil sebanyak 3 unit bus. Bus yang dibeli untuk trayek Makassar - Manado ini hanya bisa memuat penumpang sebanyak 28 orang. Berbeda dengan rute Makassar ke Sorowako yang menggunakan bus besar yang bisa memuat sekitar 40 Orang. Perbedaan mobil ini disebabkan karena jalan dari Makassar menuju ke Manado 
sangatlah sulit untu di tempuh dan dianggap tidak mampu jika menggunakan mobil bus yang besar karena jalanan menuju ke Manado banyak daerah yang dilalui memiliki jalan yang sempit dan berelokkelok. Lamanya waktu yang ditempuh untuk bisa sampai ke Manado yaitu selama 3 hari dua malam. Namun jika bus memiliki masalah selama di perjalanan seperti ban meletus, bus mogok atau terjadi bencana alam seperti longsor atau banjir biasanya waktu tempuh bisa menjadi lebih lama.

Bersamaan dengan bertambahnya trayek Makassas-Manado, pada saat itu juga didirikan kantor/perwakilan di Pangkajene Kabupaten Sidrap. Alas an didirikannya kantor di Kabupaten Sidrap karena bapak Mapong Cewang dan Istrinya merupakan orang Sidrap tepatnya di Pangkajene. Sidrap merupakan kampong dari keluarga Bapak Mapong Cewang dan Istrinya, inilah yang menjadi alasan beliau mendirikan kantor cabang PO Mega Mas di Sidrap agar mempermudah keluarga apabila ingin bepergian. Sebelum bapak Mapong Cewang berangkat ke Manado, beliau kembali ke kampung halamannya untuk merenovasi rumahnya yang akan dijadikan antor/perwakilan.

Selain penambahan Trayek, pada tahun 2001 PO Mega Mas juga menambahkan satu unit bus yang berfasilitas AC, hal ini agar dapat menambah kepuasan dan kenyamanan pelanggang. Selain itu, hal tersebut diharapkan dapat memperbaiki image perusahaan agar bisa bersaing dengan baik dengan perusahaan otobis lainnya.

Memasuki tahun 2002 PO Mega Mas terus mengalami perkembangan. Jumlah penumpang terus meningkat. Ini disebabkan karena mulai terkenalnya bus Mega Mas serta PO ini mampu bersaing dengan Bus Liman dan Litha yang merupakan bus yang sudah lebih lama telah beroperasi dari Makassar ke Sorowako. Hal ini yang menjadi tantangan untuk PO Mega Mas untuk memperkenalkan ke masyarakat agar banyak diketahui. Bedanya PO Mega
Mas dengan Litha dan Liman yang merupakan perusahaan bus yang berbentuk Saham dimana banyak orang yang memiliki sedangkan Mega Mas merupakan milik pribadi.

Pendapatan PO Mega Mas di tahun 2002 mengalami peningkatan dari pendapatan di tahun 2001. Pada tahun 2002 PO Mega Mas mengalami peningkatan pendapatan. Dimana pendapatan mencapai $\mathrm{Rp}$ 3.411.006.098 dengan biaya tetapnya sebesar Rp. 464.166.667 dan biaya Variabel sebesar Rp. 2.254.887.735. maka, besar keuntungan yang di peroleh PO Mega Mas pada tahun 2002 sebesaR Rp. 691.951.696. dari hasil tersebut, terlihat bahwa keuntungan PO Mega Mas dari 2001 menuju 2002 mengalami peningkatan.

Jadi perkembangan PO Mega Mas dari tahun 1998 - 2003 bisa dikatakan mengalami pasang surut karena banyaknya tantangan yang didapatkan. Mulai dari proses dirikannya disaat terjadi krisis ekonomi, mampu persaingan dengan PO yang lain yang sudah lebih dulu terbentuk, tantangan untuk memperkenalkan Mega Mas ke masyarakat agar banyak dikenal, serta tantangan-tantangan untuk mendirikan trayek baru seperti cabang Pangkajene Sidrap dan trayek Manado yang dirikian pada tahun 2001, hingga tantangan untuk mempertahankan/meningkatkan mendapatan yang didapatkan.

\section{Perkembangan tahun (2004-2013) : Masa Kejayaan}

Setelah PO Mega Mas mengalami banyak tantangan dan hal tersebut dapat diatasi. Pada awal tahun 2004, PO Mega Mas menambah 2 unit bus dan bus-bus pertama dilakukan pembaruan baik di mesin sampai fasilitas bus seperti pembaharuan kursi. PO Mega Mas terus mengalami perkembangan baik dalam hal pelayanan maupun dalam hal pendapatan. PO Mega Mas mulai dikenal banyak masyarakat dan banyak masyarakat yang menjadi pelanggang tetap bus Mega Mas.

Guna mendukung kelancaran operasi armada bus baru yang dibeli sudah 
menggunakan AC berbeda dengan bus Mega Mas yang pertama. Seperti pada umumnya bus dengan tipe Mercedesbenz dapat menanmpung sebanyak $40-43$ orang. Bedanya dengan bus yang lama yaitu fasilitas bus yang baru ini disediakan selimut dan bantal. PO Mega Mas terus memperbaiki pelayanannya untuk mempertahankan para pelanggang tetap agar tidak berpindah ke bus lain. Salah satunya yaitu semua bus lama dilakukan membaharuan dengan memberikan fasilitas yang sama dengan bus baru yaitu memberikan selimut dan bantal. Pada saat itu juga karena PO Mega Mas sudah memiliki banyak bus kemudian dibagi menjadi dua kelas yaitu bus kelas ekonomi yang tidak difasilitasi AC dan bus kelas VIP yang di fasilitasi AC (Jabir, 2019).

Agar kelancaran pelayanan penumpang dapat terjaga dengan baik, hamper setiap tahun diadakan pembaharuan dan penambahan unit bus baru. PO Mega Mas terus berkembang disetiap trayeknya baik trayek Makassar - Sorowako, Sidrap Sorowako, Makassar - Manado dan Sidrap Manado. Dapat dilihat dari meningkatnya jumlah pelanggang dan pendapatan yang didapatan.

Di tahun 2012, bapak Hj. Jabir mempercayakan perusahaan untuk di kelolah oleh anaknya yang bernama Hardiyansa Jabir yang baru saja lulus di bangku Sekolah Menengah Atas dan saat itu melanjutkan pendidikan di Perguruan tinggi yaitu di Universitas Fajar Makassar jurusan Manajemen. Sejak pertama kali mengemban amanah ini, agak sulit untuk beradaptasi. Mengingat usia masih terlalu muda dan belum ada pengalaman sama sekali. Tapi karena terus belajar memahami situasi sehingga lambat laun sudah paham dan mengerti pola perusahaan. Bahkan semenjak perusahaan dikelola oleh Hardiansyah, perusahaan mengalami peningkatan terutama dalam hal pelayanan. Ilmu yang didapatkan dari kampus walaupun tidak semua yang di dapatkan bisa di praktekkan dengan baik, namun belajar ilmu manajemen membuat beliau lebih paham dalam mengelola perusahaan.

Begitulah PO Mega Mas yang terus mengalami kemajuan dari tahun ke tahun di semua trayeknya dan sudah dikenal oleh masyarakat di buktikan dengan semakin banyak yang ingin menjadi pelanggang. Sehingga hal ini membuat pendapatan perusahaan terus meningkat. Seiring dengan meningkatnya pendapatan yag diperoleh, perusahaan juga terus meningkatkan pelayanannya dengan menambah dan terus memperbaharui bus dan fasilitasnya agar pelanggang bisa puas dan nyaman dengan pelayanan PO Mega Mas.

3. Perkembangan Tahun (2014-2017) : Masa Suram

Pada tahun 2014, PO Mega Mas kembali mencoba untuk menambah trayek yaitu Makassar - Malili, Makassar Timampu, dan Makassar - Mamuju. Namun hanya satu trayek yang mampu bertahan yaitu trayek Makassar Timampu. Dua trayek lainnya tidak dapat bertahan lama dikarenakan kurangnya pelanggang yang menggunakan trayek ini sehingga diputuskan untuk memberhentikan karena di anggap merugikan. bersamaan dengan itu, Trayek Manado juga mengalami masa suram dimana bapak Mapong Cewang dan istrinya sebagai pemilik sekaligus yang mengelolah PO Mega Mas cabang Manado meninggalkan kota Manado dan kembali ke Malili untuk menetap disana, hal ini hamper sama dengan kasus trayek Malili dan Mamuju yang disebabkan oleh jumlah pelanggang tidak sama seperti dulu lagi, penumpangnya semakin berkurang sehingga pendapatan pun berkurang jadi bapak Mapong Cewang memutuskan untuk kembali ke Malili untuk melanjutkan usaha budidaya ikannya yang ada disana. Karena trayek Manado mengalami kemunduran, trayek yang ada di Sidrap un ikut mengalami masa suram karena penumpang dan barang yang biasanya diberangatkan ke Manado banyak yang berasal dari Sidrap. 
Di tengah beberapa trayek PO Mega Mas yang mengalami masa suram, disisi lain trayek yang lainnya terus mengalami perekembangan seperti trayek Makassar Sorowako, Makassar - Timampu dan yang paling banyak diminati yaitu trayek Makassar - Morowali. Trayek Morowali terus mengalami perkembangan, hal ini dilihat dari perkembangan trayek ini yang terbagi beberapa daerah dan masing-masing daerah memliki kantor/perwakilan. Adapun kantor-kantor PO Mega Mas yang ada di Morowali yaitu Bungku, Sampeantaba, Emea, Bahdopi, Kolonedale, Beteleme dan Bahonsuai

\section{Kesimpulan}

Berdasarkan data hasil penelitinian, setalah melalui tahap kritik dan interpretasi, dan analisis data, maka hasil penelitian ini disimpulkan sebagai berikut.

Dampak keberadaan PO Mega Mas dapat dilihat dari kesejahteraan pemilik atau pengelola dari perusahaan otobis ini dimana dengan keberadaan PO Mega Mas ini beliau mampu memberikan kesejahteraan hidup untuk keluarganya dan juga para pegawai yang bekerja di PO Mega Mas juga mendapatkan kesajahteraan hidup seperti ada yang bisa menikah dari gaji yang dikumpulkan selama bekerja di PO Mega Mas dan ada juga yang bisa naik Haji. Selain itu, PO Mega Mas juga memberikan dampak yang baik bagi masyarakat/pelanggang karena dengan adanya perusahaan ini, mempermudah masyarakat yang ingin bepergian dengan membawa banyak barang dan juga pelanggang tidak perlu mengeluaran biaya yang banyak.

\section{DAFTAR PUSTAKA}

Adisasmita, S. A., 2011. Transportasi dan Pengembangan Wilayah.. Yogyakarta: Graha Ilmu

Brahmana, V. R. P. \&. R. K. M., 2015. Strategi Pengembangan Usaha Transportasi Bus. Jurnal Agora, p. 168.
Endar, W., n.d. Transportasi di Indonesia dari masa ke masa.. Jakarta: Cempaka Putih.

Hardiansyah, J., 2016. "Analisis Perdanaan Modal Kerja pada PO.Mega Mas”. In: Skripsi. Makassar: Fakultas Ekonomi dan Ilmu-ilmu Sosial Universitas Fajar..

Iskandar, N. P., 2017. Angkot dan Bus Minangkabau.. jakarta: Komunitas Bambu.

Jabir, H., 2019. Wawancara [Interview] (Selasa Juni 2019).

Kalli, 2019. Wawancara [Interview] (Selasa juni 2019).

Madjd, A. H. d. M. S., 2004. Pengantar Ilmu Sosial.. Yogyakarta: Ombak.

Miro, F., 2012. Pengantar Sistem Transportasi. Jakarta: Erlangga.

Muliati, 2014. "PO. PIPOSS MAKASSAR 1957 - 1975”. In: Skripsi. Makassar: Jurusan Ilmu Sejarah Fakultas Sastra Universitas Hasanuddin Makassar..

Salim, A., 2012. ManajemenTransportasi. Jakarta: Rajawali Pers.

Silalahi, U., 2012. Metode Penelitian Sosial. Bandung: Refika aditama.

Wellang, 2004. Analisis Indeksleverage Terhadap Aktiva Tetap (Pembelian Armada) Ada PO Mega Mas Di Makassar.. Makassar: Universitas Empat Lima . 